\title{
ERRATUM
}

Alison J. Golding · Giles N. Johnson

\section{Down-regulation of linear and activation of cyclic electron transport during drought}

Published online: 20 December 2003

(C) Springer-Verlag 2003

\section{Planta (2003) 218:107-114}

Owing to an unfortunate oversight, Fig. 4 was omitted and replaced by a second copy of Fig. 3 .

Fig. 4a-f PSI parameters in barley plants subjected to varying degrees of drought $(\mathbf{a}, \mathbf{c}, \mathbf{e})$ and various $\mathrm{CO}_{2}$ concentrations $(\mathbf{b}, \mathbf{d}, \mathbf{f})$. a, $\mathbf{c}, \mathbf{e}$ Open circles plants supplied with an external $\mathrm{CO}_{2}$ concentration of $2,000 \mu \mathrm{l} 1^{-1}$, closed circles $360 \mu \mathrm{l}^{-1}$. b, d, f Open circles control plants, closed circles plants subjected to $0.15 \mathrm{M}$ sorbitol, open squares $0.5 \mathrm{M}$ sorbitol. Means $\pm \mathrm{SE}$ of at least 4 replicates

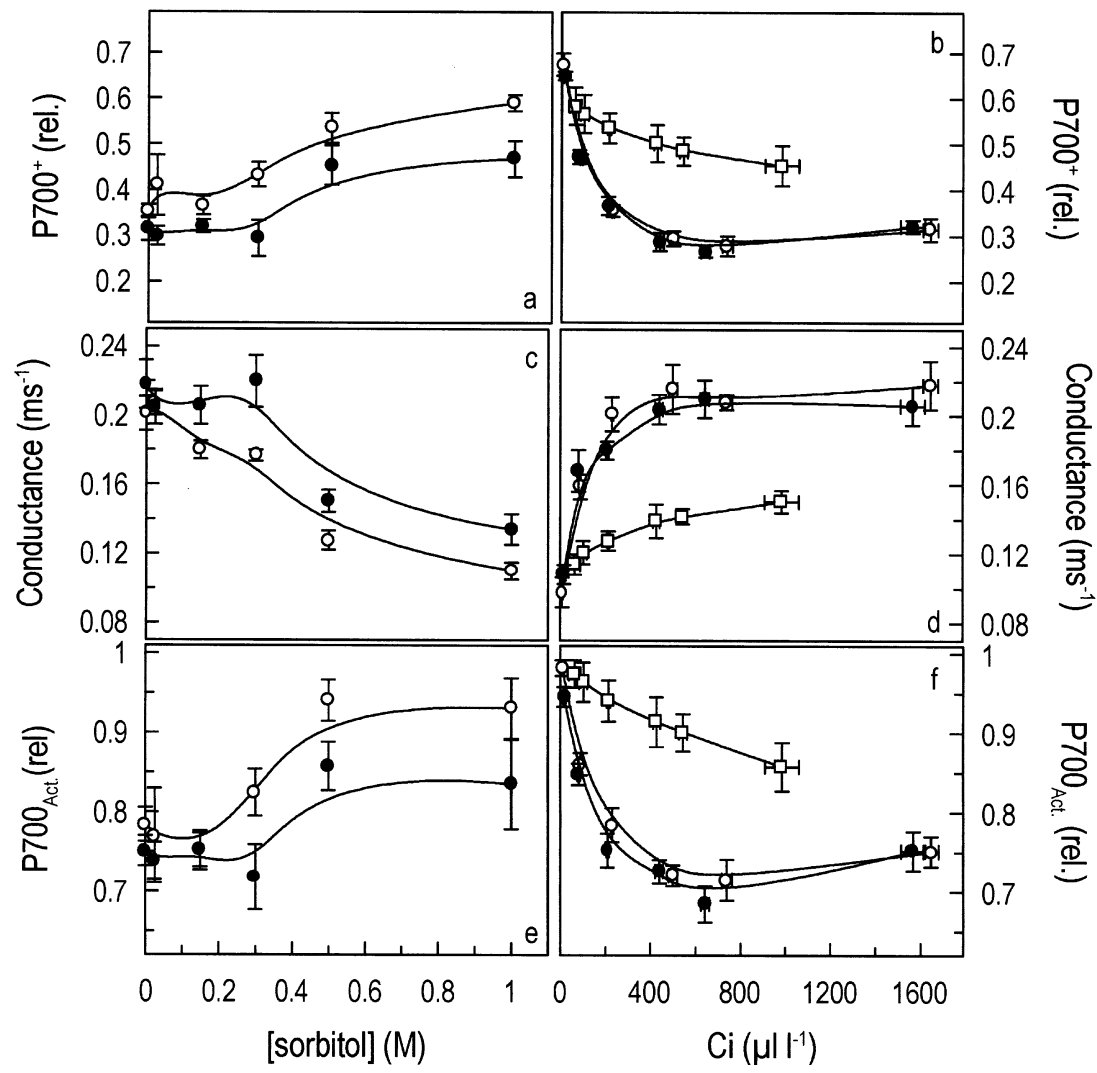

The online version of the original article can be found at http:// dx.doi.org/10.1007/s00425-003-1077-5

\section{A. J. Golding · G. N. Johnson ( $₫)$}

School of Biological Sciences, University of Manchester,

3.164 Stopford Building, Oxford Road, Manchester, M13 9PT, UK

E-mail: giles.johnson@man.ac.uk

Fax: + 44-161-2753938 